\title{
Internal quality assurance practices of nursing and midwifery training colleges and the role of regulatory bodies: The perspectives of health tutors
}

\author{
Harry Barton Essel*1, Michael Boakye-Yiadom ${ }^{2}$, Shamsudeen Mohammed ${ }^{3}$ \\ ${ }^{1}$ Educational Innovations in Science and Technology, Kwame Nkrumah University of Science and Technology, Kumasi, Ashanti \\ Region, Ghana \\ ${ }^{2}$ Institute of Educational Planning \& Administration (IEPA), University of Cape Coast, Cape Coast, Central Region, Ghana \\ ${ }^{3}$ College of Nursing and Midwifery, Ministry of Health, Nalerigu, Ghana
}

Received: December 28, 2017

DOI: $10.5430 /$ jnep.v8n10p68
Accepted: April 25, 2018

Online Published: May 15, 2018

\begin{abstract}
In the era of quality orientation, human rights, and a consumer-driven society, Nursing and Midwifery Education Institutions (NMEI) are expected to produce qualified graduates who will meet the needs and expectations of society. The aim of the study was to assess the internal quality assurance practices of Nursing and Midwifery Training Colleges (NMTCs) in the Northern Region of Ghana. An analytical cross-sectional design was adopted for the study with a sample size of eighty-eight (88). Purposive sampling method was used to select health tutors (participants) from three NMTCs in the Northern Region of Ghana. Data for the study were collected with a questionnaire and analysed. The study revealed that the NMTCs have quality assurance units/committees responsible for monitoring the quality of teaching and learning. In this study, only $39.8 \%$ of the health tutors were satisfied with the monitoring and inspection of training institutions by regulatory bodies. The results show a significant difference among the perspectives of the health tutors on the implementation of staff professional development $(\mathrm{F}(2,87)=4.74$, $p=.011)$, academic staffs motivation in the direction of refining the value of academic programs $(\mathrm{F}(2,87)=3.43, p=.037)$, working conditions of staffs $(\mathrm{F}(2,87)=3.32, p=.041)$ and the effectiveness of quality assurance systems in enhancing the quality of teaching and assessment $(\mathrm{F}(2,87)=3.27, p=.043)$. There is the need to ensure uniformity in staff professional development, working conditions, and motivation of health tutors in the training institutions. Regulatory bodies must intensify the monitoring of NMTCs and offer accreditation to new NMTCs based on the state of educational resources and facilities.
\end{abstract}

Key Words: Nursing and Midwifery Training College, Internal quality assurance practices, Northern Region, Nursing and Midwifery Council of Ghana, Health tutors

\section{INTRODUCTION}

In Ghana, courses leading to the registration of a person as a nurse or a midwife typically last for three years in Nursing and Midwifery Training Colleges and four years in universities. All nursing and midwifery programs in Ghana contain a clinical component, and trainees of these programs must pass a licensing examination conducted by the Nursing and Midwifery Council of Ghana in order to be registered as nurses. Quality assurance (QA) is one of the mechanisms established by education institutions to guarantee that graduates achieve adequate standards of education and training. In the era of quality orientation, human rights, and a consumer-

\footnotetext{
*Correspondence: Harry Barton Essel; Email: bartoness@gmail.com; Address: Educational Innovations in Science and Technology, Kwame Nkrumah University of Science and Technology, Kumasi, Ashanti Region, Ghana.
} 
driven society, Nursing and Midwifery Education Institutions (NMEI) are expected to produce qualified graduates who will meet the needs and expectations of society. ${ }^{[1]}$ Nurses are to make the care of patients their first concern, treating them as individuals and respecting their dignity. Notwithstanding these great expectations, reports of unsafe, poor, and heartless care by nurses and midwives are heard day by day, in the media, at professional conferences, and in everyday conversations. As these reports of appalling care and mismanagement unfold, questions are being asked about the quality of nursing education and the competence of newly qualified nursing graduates. ${ }^{[2]}$ The president of the Ghana Registered Nurses and Midwives Association (GRNMA), Kwaku Asante-Krobea, in 2011 expressed worry over what he described as the poor attitude of some nurses towards their clients. ${ }^{[3]}$ The concern for quality in nursing and midwifery education is further necessitated by an increase in enrolment by NMTCs.

To ensure quality supervision and regulation of nursing and midwifery education in Ghana, the government of Ghana in 1972 established the Nurses and Midwives Council (NMC) of Ghana to regulate the training and practice of nursing and midwifery in the country. The name of the Council changed to Nursing and Midwifery Council of Ghana following the enactment of the Health Professions Regulatory Bodies Act, 2013 (Act 857). ${ }^{[4]}$ In 1993 an additional external quality assurance agency, the National Accreditation Board (NAB) of Ghana was formed. The NAB is an agency responsible for the regulation, supervision, and accreditation of tertiary institutions in Ghana. ${ }^{[5]}$ To demonstrate the desire to guarantee external quality assurance in Nursing and Midwifery Training Colleges, the Ministry of Health in 2013 established the KNUST-Ministry of Health partnership, mandating the Kwame Nkrumah University of Science and Technology, Kumasi (KNUST) to supervise the training of nurses and midwives in the various colleges in Ghana. In 2015, the ministry of health inaugurated the Health Training Institutions Secretariat (HTIS) to supervise the enrolment of students in all NMTCS in Ghana and the tuition fees to be charged. ${ }^{[6]}$

However, a literature search revealed a dearth of studies and inadequate information on the internal quality assurance practices of Nursing and Midwifery Training Colleges (NMTCs) in Ghana. The European Association for Quality Assurance in Higher Education (2010) stated that a wellinstituted external quality assurance system would not lead to real improvement in quality in the absence of a strong internal quality assurance in an institution. ${ }^{[7,17]}$ To ensure the quality of their programmes, awards, and graduates, education institutions need to establish internal quality assurance systems and processes to supplement external quality assur-

Published by Sciedu Press ance systems. ${ }^{[8]}$ Thus far, little is known about the internal quality assurance practices of Nursing and Midwifery Training Colleges in Ghana. This study, therefore, assessed health tutors' perspectives of internal quality assurance policies and practices of Nursing and Midwifery Training Colleges in the Northern Region of Ghana.

\section{METHODS}

The study adopted a quantitative analytical cross-sectional design. It was conducted from 15th June to 30th September 2017 in three Nursing and Midwifery Training Colleges (NMTCs) in the Northern Region of Ghana, namely Tamale Nurses and Midwives Training College in the Tamale Metropolis; Nalerigu College of Nursing and Midwifery in the East Mamprusi District; and, Yendi College of Health Sciences in the Yendi Municipal Assembly. The Tamale Nurses and Midwives Training College currently runs two programs: Registered General Nursing and Registered General Midwifery. Nalerigu College of Nursing and Midwifery offers three programmes namely: Registered General Nursing, Registered Midwifery, and Nurse Assistant Clinical. Yendi College of Health Sciences was established in 2007 as a Health Assistant Training School to train Nurse Assistants (clinical) to augment the shortage of healthcare professionals, particularly nurses.

\subsection{Population}

The target population for the study was all the Health Tutors in the NMTCs in Northern Region. The study included tutors who had worked in the selected institutions for more than one academic year.

\subsection{Sample size and sampling procedure}

Yamane's mathematical formula for sample size determination was used to estimate a sample size of 88 based on a population of 112 Health Tutors, under an assumption of 95\% confidence interval (CI) and 5\% level of precision (alpha $=0.05$ ). The estimated sample size for the study was allocated to each college using a proportional method centred on the number of health tutors in each of the three colleges. Purposive sampling method was used to select the apportioned number of health tutors (participants) from the three Nursing and Midwifery Training Colleges (see Figure 1). The purposively selected health tutors were vice principals, academic coordinators, program heads, clinical coordinators, examination coordinators, and tutors who had worked in the selected institutions for more than one academic year. These tutors were selected because they are well equipped with accurate and the desired information, knowledge, or experience relevant to the objectives of the study. 


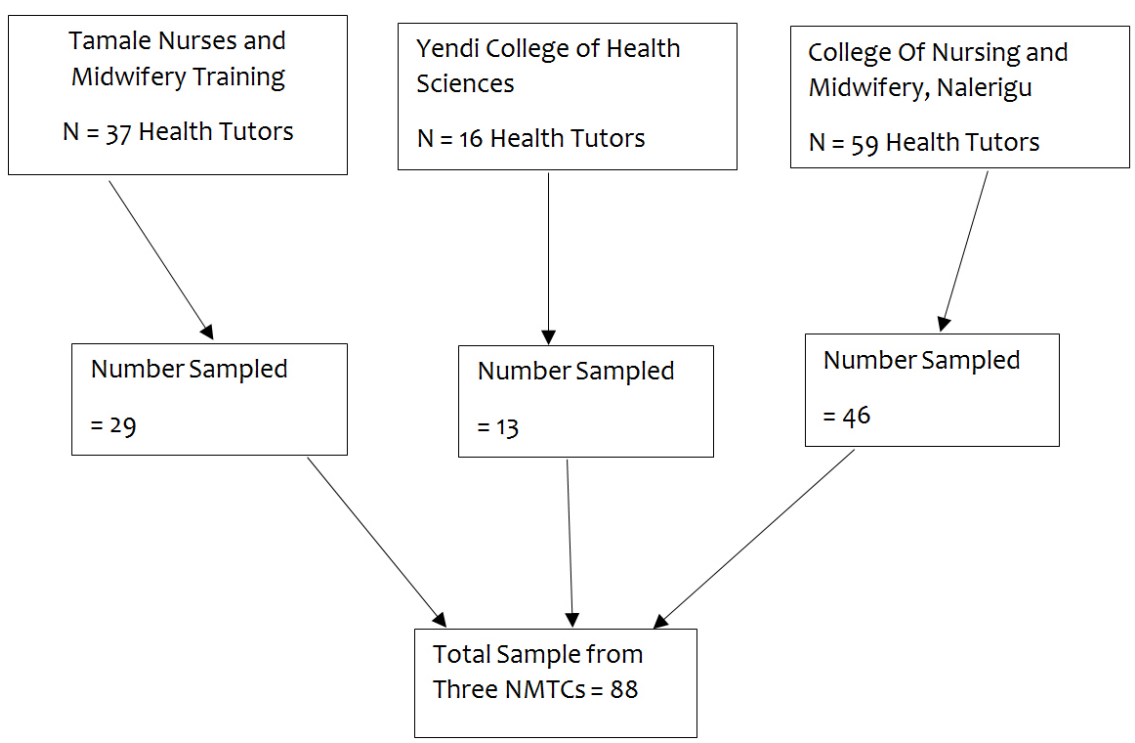

Figure 1. Flow chart of the proportional sampling of health tutors

\subsection{Data collection instruments}

Data for this study were collected with a structured questionnaire. The questionnaire consisted largely of closed questions on the internal quality assurance practices of Nursing and Midwifery Training Colleges. It contained items on respondent's Profile; institutional quality assurance policies and practices; health tutors perspectives on internal quality assurance mechanisms and procedures; and, the role of regulatory bodies in improving internal quality assurance systems of NMTCs. The questionnaire was administered to 88 health tutors in the three NMTCs with the assistance of a health tutor in each of the colleges. The questionnaires were hand administered to the health tutors. This provided an opportunity for the researcher and data collection assistants to address concerns of the study participants.

\subsection{Data analysis method}

Descriptive statistics were reported as percentages, frequencies, means, and standard deviations. Analysis of Variance (1-way ANOVA) was used to measure difference among the perspectives of health tutors on internal quality assurance practices at the different colleges. The significance level was set at .05 .

\section{Results}

To achieve the objectives of the study, data were collected on the views and perceptions of tutors of Nalerigu NMTC, Tamale NMTC, and Yendi College of Health Science (CHS) on internal quality assurance practices in their respective institutions. Of the eighty-eight (88) questionnaires that were administered, the research team was able to retrieve eightythree (83) within three weeks. Based on this, the response rate was calculated to be $94 \%$.

\subsection{Background characteristics of the participants}

The study sampled $40(48.2 \%)$ health tutors from Nalerigu NMTC, 28 (33.7\%) from Tamale NMTC, and 15 (18.1\%) from Yendi CHS. More than half of the participants in this study were holders of bachelor's degree $(69.9 \%)$. The Majority $(78.3 \%)$ of the health tutors had 1-4 years teaching experience and were predominantly males $(69.9 \%)$ (see Table 1).

\subsection{Internal quality assurance policies, systems, and pro- cedures}

The study examined the internal quality assurance policies, systems, and procedures in the three Nursing and Midwifery Training Colleges. Participants were asked to indicate the presence or absence of a number of policy instruments in their respective colleges. The response of the health tutors are shown in Table 2.

More than half (Nalerigu NMTC 82.5\%, Tamale NMTC $78.6 \%$, and Yendi CHS 66.7\%) of the participants in each of the colleges said there was a quality assurance unit/committee in the school where they teach. The majority of the tutors of the three colleges indicated their schools undergo regular staff meeting (Nalerigu NMTC 85\%, Tamale NMTC 82\%, and Yendi CHS 73\%) and have significant quality performance pointers or canons for teaching (Nalerigu NMTC 73\%, Tamale NMTC 79\%, and Yendi CHS $60 \%$ ). The presence of a scheme to ensure good governance, transparency, and answerability were rated low among participants from Nalerigu NMTC (41.0\%) and Yendi CHS (33.3\%). Furthermore, Nalerigu NMTC scored the lowest percentage (42.5\%) on tactical scheduling with clear goals, objectives and mission for research, learning and teaching. 
Table 1. Characteristics of the study participants

\begin{tabular}{llll}
\hline Variables & Categories & Frequency (n = 83) & Percent (\%) \\
\hline \multirow{3}{*}{ College/Institution } & Nalerigu NMTC & 40 & 48.19 \\
& Tamale NMTC & 28 & 33.73 \\
& Yendi CHS & 15 & 18.07 \\
& $20-30$ years & 28 & 33.73 \\
Age of respondents & $31-40$ years & 48 & 57.83 \\
& $41-50$ years & 5 & 6.02 \\
Gender of respondents & Above 50 years & 2 & 2.41 \\
& Male & 58 & 69.88 \\
Highest educational qualification & Female & 25 & 30.12 \\
& Diploma & 7 & 8.43 \\
How long have you been academic staff & Bachelor degree & 58 & 69.88 \\
& Master's degree & 16 & 19.28 \\
& PhD & 2 & 2.41 \\
\end{tabular}

Table 2. Internal quality assurance policies, systems, and measures of NMTCS in Northern Region $(\mathrm{n}=83)$

\begin{tabular}{|c|c|c|c|c|}
\hline Internal Quality Improvement Policy & Responses & Nalerigu NMTC (\%) & Tamale NMTC (\%) & Yendi CHS (\%) \\
\hline \multirow{3}{*}{ Quality assurance Unit/committee } & Yes & 82.50 & 78.57 & 66.67 \\
\hline & No & 12.50 & 3.57 & 13.33 \\
\hline & Don’t know & 5.00 & 17.86 & 20.00 \\
\hline \multirow{3}{*}{$\begin{array}{l}\text { Regular staffs meeting to discuss the quality } \\
\text { of education }\end{array}$} & Yes & 85.00 & 82.14 & 73.33 \\
\hline & No & 10.00 & 10.71 & 20.00 \\
\hline & Don’t know & 5.00 & 7.14 & 6.67 \\
\hline \multirow{3}{*}{$\begin{array}{l}\text { Pivotal values performance indicators or } \\
\text { standards for teaching }\end{array}$} & Yes & 72.50 & 78.57 & 60.00 \\
\hline & No & 20.00 & 7.14 & 6.67 \\
\hline & Don’t know & 7.50 & 14.29 & 33.33 \\
\hline \multirow{3}{*}{$\begin{array}{l}\text { Quality assurance policies, manuals and } \\
\text { guidelines }\end{array}$} & Yes & 45.00 & 64.29 & 53.33 \\
\hline & No & 35.00 & 3.57 & 6.67 \\
\hline & Don’t know & 20.00 & 32.14 & 40.00 \\
\hline \multirow{3}{*}{$\begin{array}{l}\text { Strategic planning with a clear goals, } \\
\text { objectives and mission for research, learning } \\
\text { and teaching }\end{array}$} & Yes & 42.50 & 78.57 & 53.33 \\
\hline & No & 40.00 & 7.14 & 33.33 \\
\hline & Don’t know & 17.50 & 14.29 & 13.33 \\
\hline \multirow{3}{*}{$\begin{array}{l}\text { A scheme to ensure reputable governance, } \\
\text { transparency, and answerability }\end{array}$} & Yes & 41.03 & 53.57 & 33.33 \\
\hline & No & 43.59 & 32.14 & 53.33 \\
\hline & Don’t know & 15.38 & 14.29 & 13.33 \\
\hline
\end{tabular}

\subsection{The perspectives of health tutors on the internal quality assurance practices of NMTCs in northern region}

The participants of this study were asked to rate a number of internal quality assurance practices in their respective schools from 1 to 4 (1 implies strongly disagree (SD), 2 implies disagree (D), 3 implies agree (A) and 4 implies strongly agree (SA)). The averages of the ratings from the participants were computed and the results presented in Table 3.

Published by Sciedu Press

Sharing of vision by management for the enhancement of quality teaching (Mean $=3.03$ ) and the availability and maintenance of physical facilities (Mean $=3.00$ ) were the highest rated quality assurance practices in the schools. The results show a low average for effective communication of quality assurance system to staffs, students, and stakeholders (Mean $=2.33$ ); and the connection of quality assurance systems to the overall mission and goals of the schools (Mean $=2.40$ ). 
Table 3. Perspectives on health tutors on the internal quality assurance practices of NMTCs

\begin{tabular}{|c|c|c|}
\hline Internal quality assurance practices & Mean & SD \\
\hline Availability and maintenance of physical facilities to ensure quality teaching and learning & 3.00 & .748 \\
\hline Management at all levels express the identical vision for advancing quality of learning and teaching & 3.03 & .723 \\
\hline professional development programs for Staff has been implemented successfully & 2.89 & .732 \\
\hline Participative policymaking style for guaranteeing quality at the college level & 2.83 & .746 \\
\hline Quality assurance ingenuities are implemented in a slapdash means with impracticable time frames & 2.61 & .778 \\
\hline Quality assurance system is clear, rigorous and understood by staffs & 2.60 & .748 \\
\hline Academic staff Motivation to refining the value of academic programmes & 2.48 & .801 \\
\hline Working circumstances of staffs encourage a climate that improves the quality of learning and teaching & 2.53 & .770 \\
\hline Effective communication of quality assurance system to students, staffs and other key stakeholders & 2.33 & .720 \\
\hline Quality assurance schemes are helpful for the enhancement of the quality teaching and assessment & 2.48 & .721 \\
\hline Quality assurance schemes are connected to the inclusive goals and mission & 2.40 & 644 \\
\hline
\end{tabular}

3.4 The role of regulatory bodies in improving quality improving the quality of Nursing and Midwifery education in of nursing and midwifery education in Northern Re- Northern Region. Participants were asked to rate the extent to gion

The study sought the views of participants on the role of Table 4 presents the descriptive summary of the responses of regulatory bodies (i.e. NMC, KNUST, HTIS, and NAB) in the participants.

Table 4. The role of regulatory bodies in improving the internal quality assurance practices of NMTCs in Northern Region $(\mathrm{n}=83)$

\begin{tabular}{|c|c|c|c|c|}
\hline External Quality Assurance Roles & VD (\%) & D (\%) & $\mathrm{S}(\%)$ & VS (\%) \\
\hline Setup standards for the admission of students & 3.61 & 36.14 & 51.81 & 8.43 \\
\hline Monitoring and inspection of training institutions & 9.64 & 48.19 & 39.76 & 2.41 \\
\hline $\begin{array}{l}\text { Establish standards and provide guidelines for the development of curricula } \\
\text { for the training of nurses }\end{array}$ & 2.41 & 28.92 & 63.86 & 4.82 \\
\hline Periodic reviews of programmes and curriculum & 6.02 & 30.12 & 59.04 & 4.82 \\
\hline $\begin{array}{l}\text { Ensure that qualifications obtained from these institutions are comparable to } \\
\text { international standards }\end{array}$ & 3.61 & 25.30 & 56.63 & 14.46 \\
\hline Ensure nursing and midwifery institutions are accredited & 2.41 & 37.35 & 56.63 & 3.61 \\
\hline $\begin{array}{l}\text { Accredit institutions depending on the state of facilities and resources } \\
\text { available to the institutions }\end{array}$ & 4.82 & 59.04 & 32.53 & 3.61 \\
\hline $\begin{array}{l}\text { Ensure the training of nurses and midwives is carried out at approved } \\
\text { educational institutions }\end{array}$ & 3.61 & 26.51 & 61.45 & 8.43 \\
\hline
\end{tabular}

Note. VD = Very dissatisfied, D = Dissatisfied, S = Satisfied, VS = Very satisfied

In this study, 51.8\% of the participants were satisfied with the role of regulatory bodies in setting up standards for the admission of students into the training institutions. In addition, fifty-three $(63.9 \%)$ of the participants were satisfied with the role of the regulatory bodies in establishing standards and providing guidelines for the development of curricula for the training of nurses. The results show that $59 \%$ of the participants were dissatisfied with the role of regulatory bodies in accrediting institutions based on the state of facilities and resources available to the institutions and only $39.8 \%$ were satisfied with the monitoring and inspection of training institutions by regulatory bodies.

\subsection{Comparison of the perspectives of participants from the three institutions on internal quality assurance practices in their respective schools}

Using ANOVA, we compared the average ratings of the study participants' perspectives on the internal quality assurance practices of their respective schools. Table 5 illustrates the ANOVA results for all the internal quality assurance practices of the schools. 
Table 5. Comparison of the Perspectives of health tutors on Internal Quality Assurance Practices

\begin{tabular}{|c|c|c|c|c|}
\hline Internal Quality Assurance Measures & Colleges & Mean & $\mathbf{F}$ & $p$ \\
\hline \multirow{3}{*}{$\begin{array}{l}\text { Availability and maintenance of physical facilities to ensure quality teaching } \\
\text { and learning }\end{array}$} & Nalerigu NMTC & 3.05 & \multirow{3}{*}{1.17} & \multirow{3}{*}{.315} \\
\hline & Tamale NMTC & 3.07 & & \\
\hline & Yendi CHS & 2.73 & & \\
\hline \multirow{3}{*}{$\begin{array}{l}\text { Management at all levels express the identical vision in advancing quality of } \\
\text { learning and teaching }\end{array}$} & Nalerigu NMTC & 3.15 & \multirow{3}{*}{1.34} & \multirow{3}{*}{.267} \\
\hline & Tamale NMTC & 3.00 & & \\
\hline & Yendi CHS & 2.80 & & \\
\hline \multirow{3}{*}{ Staff professional development has been implemented successfully } & Nalerigu NMTC & 3.05 & \multirow{3}{*}{4.74} & \multirow{3}{*}{.011} \\
\hline & Tamale NMTC & 2.92 & & \\
\hline & Yendi CHS & 2.40 & & \\
\hline \multirow{3}{*}{ Participative policymaking style for guaranteeing quality at the college level } & Nalerigu NMTC & 2.78 & \multirow{3}{*}{0.35} & \multirow{3}{*}{.708} \\
\hline & Tamale NMTC & 2.90 & & \\
\hline & Yendi CHS & 2.73 & & \\
\hline \multirow{3}{*}{$\begin{array}{l}\text { Quality assurance ingenuities are executed in a slapdash means with } \\
\text { impracticable time frames }\end{array}$} & Nalerigu NMTC & 2.62 & \multirow{3}{*}{0.08} & \multirow{3}{*}{.924} \\
\hline & Tamale NMTC & 2.57 & & \\
\hline & Yendi CHS & 2.66 & & \\
\hline \multirow{3}{*}{ Quality assurance scheme is rigorous, clear and understood by staff } & Nalerigu NMTC & 2.46 & \multirow{3}{*}{0.32} & \multirow{3}{*}{.724} \\
\hline & Tamale NMTC & 2.65 & & \\
\hline & Yendi CHS & 2.61 & & \\
\hline \multirow{3}{*}{ Academic staff motivation to refining the academic programme quality } & Nalerigu NMTC & 2.70 & \multirow{3}{*}{3.43} & \multirow{3}{*}{.037} \\
\hline & Tamale NMTC & 2.36 & & \\
\hline & Yendi CHS & 2.13 & & \\
\hline \multirow{3}{*}{$\begin{array}{l}\text { Working conditions of staff encourage a climate that improves the value of } \\
\text { learning and teaching }\end{array}$} & Nalerigu NMTC & 2.75 & \multirow{3}{*}{3.32} & \multirow{3}{*}{.041} \\
\hline & Tamale NMTC & 2.32 & & \\
\hline & Yendi CHS & 2.33 & & \\
\hline \multirow{3}{*}{$\begin{array}{l}\text { Effective communication of quality assurance system to staff, students, and } \\
\text { other key stakeholders }\end{array}$} & Nalerigu NMTC & 2.22 & \multirow{3}{*}{1.65} & \multirow{3}{*}{.199} \\
\hline & Tamale NMTC & 2.54 & & \\
\hline & Yendi CHS & 2.27 & & \\
\hline \multirow{3}{*}{$\begin{array}{l}\text { Quality assurance schemes are supportive for the augmentation of quality } \\
\text { teaching and assessment }\end{array}$} & Nalerigu NMTC & 2.07 & \multirow{3}{*}{3.27} & \multirow{3}{*}{.043} \\
\hline & Tamale NMTC & 2.60 & & \\
\hline & Yendi CHS & 2.54 & & \\
\hline & Nalerigu NMTC & 2.39 & & \\
\hline Quality assurance schemes are connected to the overall goals and mission & Tamale NMTC & 2.43 & 0.02 & .978 \\
\hline & Yendi CHS & 2.40 & & \\
\hline
\end{tabular}

The results show a significant difference among the perspectives of the health tutors on the implementation of staff professional development $(\mathrm{F}(2,87)=4.74, p=.011)$, academic staffs motivation toward refining the value of academic programs $(\mathrm{F}(2,87)=3.43, p=.037)$, working conditions of staffs $(\mathrm{F}(2,87)=3.32, p=.041)$ and the effectiveness of quality assurance systems in enhancing the quality of teaching and assessment $(\mathrm{F}(2,87)=3.27, p=.043)$. The results indicate that health tutors of Nalerigu NMTC as compared with their colleagues from the other NMTCs are more satis-

Published by Sciedu Press fied with the level of motivation ( $M=2.70, \mathrm{SD}=0.72)$, staff professional development $(\mathrm{M}=3.05, \mathrm{SD}=0.67)$ and working conditions $(\mathrm{M}=2.75, \mathrm{SD}=0.74)$ in the institution. No significant transformation was identified in the mean scores of participants' perspectives on the other internal quality assurance practices of the NMTCs.

\section{Discussion}

This is the first empirical study to assess internal quality assurance practices of Nursing and Midwifery Training Col- 
leges in Ghana. In the study, a greater number of the health tutors from the three NMTCs reported the presence of a quality assurance unit/committee in their schools. These quality assurance units are in charge of monitoring and evaluation of the quality of teaching and learning to ensure graduates attain adequate standards of education and training. The World Health Organization (WHO) recommends the appointment of a quality assurance committee responsible for internal auditing, monitoring, and evaluation of quality assurance systems. ${ }^{[10]}$ A large percentage of the health tutors in the three institutions revealed that the schools organise consistent staff summits to discourse the quality of student learning and teaching. These meetings present a platform to assess and evaluate the progress of quality assurance interventions in the Nursing and Midwifery Training Colleges. It offers an opportunity for staff to brainstorm new ideas, discuss areas of change, and solve specific problems. In contrast, a study in Ethiopia reported infrequent staff meetings in three educational institutions in Ethiopia. ${ }^{[1]}$ The practice of good governance, transparency, and accountability was poorly rated in Nalerigu NMTC and Yendi CHS. The low score indicates most of the health tutors in these institutions are unhappy with the level of transparency, accountability, and governance in the schools. The absence of transparency, accountability and good governance hurdle the effective utilisation and allocation of resources. In Bangladesh, for instance, poor governance in education resulted in geographical and social gaps in the quality of educational services. ${ }^{[12]}$

'Sharing of vision by management at all levels for the enhancement of quality teaching' was the highest rated internal quality assurance practice in this study. This finding is inconsistent with a study in Ethiopia which reported a lower mean score (mean $=2.78$ ), indicating management at all levels did not express the identical vision for advancing the quality of learning and teaching. The varying mean scores could be due to the difference in study settings as the Ethiopian study was conducted among university academic staff. Inadequate physical resources and infrastructural challenges militate against the implementation of quality assurance policies. ${ }^{[13,14]}$ Physical facilities including information technology (IT), teaching/learning resources and nursing and midwifery equipment must be sufficient and appropriate to support the purposes of NMTCs. ${ }^{[10]}$ In the present study, availability and maintenance of physical facilities was the second highest rated internal quality assurance practice in the NMTCs. The health tutors indicated that the physical facilities of the NMTCs were adequate to support the purposes of the institutions. The presence of adequate physical facilities provides a foundation for quality teaching/learning and assessment of students.
A low mean score was recorded for 'effective communication of quality assurance strategies to staff, students, and stakeholders' and the 'connection of quality assurance systems to the overall mission and goals of the schools'. This finding is consistent with a study by Geda (2014) who reported poor communication of existing quality assurance system to staff, students, and stakeholders in three universities in Ethiopia. ${ }^{[11]}$ Managers of NMTCs have a duty to provide staffs, students, and stakeholders with up to date, unbiased, and objective information about the quality assurance strategies of the institution and their role in it. Poor communication impedes the implementation of quality assurance policies, models, and programmes.

The study identified significant dissimilarities in the internal quality assurance practices of the NMTCs, albeit, they are regulated by the same regulatory bodies. The health tutors of Nalerigu NMTC were more satisfied with the staff professional development, motivation, and the working conditions of staffs in the institution as compared with their colleagues from Tamale NMTC and Yendi CHS. A study in Ghana by Alhassan, Beyere, and Nketiah-amponsah (2017) reported that, health tutors described staff motivation to include good working relationship with school administration, opportunity to pursue higher education, and appreciation by school management in the form of allowances (fuel, vehicle maintenance, travel and rent allowances). ${ }^{[9]}$ The current study found a significant difference in the perspectives of the health tutors from the three NMTCs on "Implementation of staff professional development", "the motivation of academic staffs", "working conditions of staffs", and the "effectiveness of quality assurance schemes in enhancing the quality of teaching and assessment".

The Nursing and Midwifery Council of Ghana (N\&MC), Health Training Institutions Secretariat (HTIS), National Accreditation Board (NAB), and Kwame Nkrumah University of Science and Technology (KNUST) regulate the training of nurses and accreditation of NMTCs in Ghana. These regulatory bodies ensure NMTCs produce nurses and midwives who are competent and can provide safe nursing care to patients. The regulatory bodies also set the entry requirements for the admission of students into the NMTCs. The health tutors were satisfied with the role of the regulatory bodies in setting up standards for the admission of students into the training institutions. This could imply that the health tutors are familiar with the entry requirements and students are admitted based on the criteria set by the regulatory bodies. This practice ensures that students who gain admission into these colleges are capable of going through the academic work required of nurse trainees. In addition, NMTCs in Ghana conduct written and oral interviews for applicants who have 
met the entry requirements into the colleges. Applicants who are successful in these examinations are offered admission to study nursing. [15]

Furthermore, the health tutors were satisfied with the role of the regulatory bodies in establishing standards and providing guidelines for the development of curricula for the training of nurses. The curricula for the training of nurses at the NMTCs in Ghana are developed and updated by the Nursing and Midwifery Council of Ghana. This ensures uniformity in the training offered at all the NMTCs in the country. The content of the nursing curricula focuses on both theoretical and practical knowledge. This practice is similar to what exists in India, where the Indian Nursing Council prescribes the syllabus, including unit plan and hours of each subject, the scheme of examination and admission criteria of nursing training institutions. Minimum standards are also set for the physical facility, teaching facility and clinical facility to start a nursing programme. ${ }^{[1]}$

Results of the present study revealed that health tutors were not satisfied with the role of regulatory bodies in the accreditation of NMTCs. Accreditation of health training institutions ought to take into account educational resources available for the student population and for the delivery of curriculum, including the library, lecture halls, laboratories, computers and provision for field practice. ${ }^{[1]}$ The responses of the health tutors did not support the suggestion that accreditation of new NMTCs takes into consideration the state of facilities and resources such as adequate classrooms, skills laboratories, and well-equipped libraries available to the institutions. A study in Ghana by Bell et al. (2014) found that equipment in skills laboratories, textbooks in libraries, and computer laboratories of faculties offering nursing programmes were below standard and out-of-date. ${ }^{[16]}$

Additionally, regulatory bodies of NMTCs are expected to monitor and inspect the activities and programmes of the training institutions to ensure they implement and comply

\section{REFERENCES}

[1] WHO. Quality Assurance and Accreditation of Nursing and Midwifery Educational Institutions [Internet]. India; 2008. Available from: http://apps . searo.who.int/PDS_DOCS/B3156.pdf

[2] Willis Commission. Quality with Compassion: Report of the Willis Commission [Internet]. UK; 2012. Available from: https ://www . nursingtimes . net/download?ac $=1255026$

[3] Krobea AK. Ghana Registered Nurses' Association: Celebration of International Nurses' Day and GRNA Nurses' Week 2011 [Internet]. The Nurse/Midwife under the Microscope. 2011 [cited 2017 Jan 28]. p. 1-6. Available from: http://www.ghananurses.org/ind.pd f

Published by Sciedu Press with quality standards. The health tutors in this study were not satisfied with the way the regulatory bodies conduct monitoring and inspection at the NMTCs. They perceived monitoring and inspection by the regulatory bodies to be infrequent and ineffective. In Myanmar, the body that regulates nursing and midwifery education monitors quality in the institutions through regular school visits, feedback from students, consumers and service users (hospitals, clinics) and provides feedback to the schools and faculties. ${ }^{[1]}$

\section{Conclusion}

The findings of the study brought to light the internal quality assurance practices of Nursing and Midwifery Training Colleges in the Northern Region of Ghana. The institutions had quality assurance units/committees. However, significant differences were observed among the perspectives of the health tutors on some internal quality assurance practices of the NMTCs. The researchers, therefore, recommend that there is the need to ensure uniformity in staff professional development, working conditions, and motivation of health tutors in the training institutions. Health tutors were moderately satisfied with the role of regulatory bodies in improving internal quality assurance practices of the NMTCs. Nevertheless, regulatory bodies must intensify the monitoring of training institutions through regular visits to the institutions. Additionally, accreditation of new NMTCs must take into consideration the physical facilities, teaching facilities, clinical facilities, and the educational resources of the institutions.

\section{ACKNOWLEDgements}

The authors wish to thank principals of the training institutions and the health tutors who participated in the study. We also want to thank Alhassan Mohammed Muhib of Nalerigu NMTC, Sumani Fuseini of Yendi CHS, and Abraham Akoto of Tamale NMTC, for their support during data collection.

\section{CONFlicts OF InTEREST Disclosure}

The authors declare that there is no conflict of interest.
[4] Nursing and Midwifery Council of Ghana. Mandate [Internet] Ghana; 2016 [cited 2016 Nov 15]. Available from: https://ww w.nmcgh.org/t3f/en/mandate

[5] National Accreditation Board. About us [Internet]. 2016 [cited 2016 Oct 25]. Available from: http://www.nab.gov.gh/about-us

[6] Government of Ghana. Government Commissions Health SecretariatGovernment of Ghana [Internet]. 2017 [cited 2017 Nov 24]. Available from: http://www.ghana.gov.gh/index.php/med ia-center/news/2167-government-commissions-healt $\mathrm{h}$-secretariat

[7] European Association for Quality Assurance in Higher Education. Standards and Guidelines for Quality Assurance in the European 
Higher Education Area [Internet]. 3rd editio. Helsinki, Finland; 2009. 7-39 p. Available from: http: //www. enqa.eu/pubs. lasso

[8] Materu P. Higher Education Quality Assurance in Sub-Saharan Africa: Status, Challenges, Opportunities, and Promising Practices [Internet]. Vol 124. Washington D.C., USA: world Bank; 2007. 1-69 p. Available from: http://www.eua.be/Libraries/qa-conne ct/wp124_qa_higher_edu_africa.pdf?sfvrsn=0

[9] Alhassan RK, Beyere CB, Nketiah-amponsah E. Perceived needs of health tutors in rural and urban health training institutions in Ghana: Implications for health sector staff internal migration control. PLOS ONE. 2017; 12(10): 1-17. Available from: http://journals.plos.org/plosone/article?id=10. 1371/journal pone. 0185748

[10] WHO. Guidelines on Quality Assurance and Accreditation of Nursing and Midwifery Educational Institutions [Internet]. New Delhi, India; 2010. Available from: http://www.searo.who.int/enti ty/nursing_midwifery/documents/sea_nur_464/en/

[11] Geda AG. Quality Assurance Policy and Practice in Higher Education Institutions in Ethiopia [Internet]. University of South Africa; 2014.

[12] Khodary Y. Towards good governance in basic education: a case stduy of fayoum [Internet]. Fayoum, Egypt; 2014. Avail- able from: http://www.socialcontract.gov.eg/media/Me diaCenter/cfac6fd2-68b9-4d47-8c0a-fc158b18efb4.pdf

[13] Seniwoliba JA, Richard N. Educational Research and Reviews - an analysis of the quality assurance policies in a ghanian university. Educ Res Rev. 2005; 10(16): 2331-9.

[14] Mensah MA. Implementation of Internal Quality Assurance in Polytechnics: Evidence from Ghana. Eur Sci J [Internet]. 2016; 12(19): 221-43. Available from: http://eujournal.org/index.php/ esj/article/view/7728/7449

[15] Arthur YA. Internal Quality Assurance: Does It Exist in Ghanaian Nurses Training Colleges? Res Humanit Soc Sci [Internet]. 2014; 4(19): 60-4. Available from: http://iiste.org/Journals/ind ex.php/RHSS/article/download/15763/16557

[16] Bell SA, Arbor A, Rominski S, et al. An Analysis of Nursing Education in Ghana: Priorities for Scaling-up the Nursing Workforce. Nurs Heal Sci 2013 [Internet]. 2014; 15(2): 244-9. Available from: http://onlinelibrary.wiley.com/doi/10.1111/nhs . 12026/abstract

[17] Essel H, Boakye-Yiadom M, Kyeremeh F. Assessing Students' Experiences of Internal Quality Assurance Practices in Selected Private Higher Education Institutions. International Journal of Science and Research. 2018; 7(2): 804-809. 